\title{
A European Urban Regeneration through Intelligent Applications
}

\author{
Antonietta Ivona \\ University of Bari Aldo Moro, Department of Economy and Finance, Piazza Umberto I, 1, 70121 Bari BA, Italy \\ antonietta.ivona@uniba.it
}

Received: 7 November 2020; Revised: 24 November 2020; Accepted: 3 December 2020;

Published online: 10 December 2020

\begin{abstract}
With the advent of new technologies, cultural heritage can be experienced within a more complex tourist offer based on highly personalized products, tailored to the needs of visitors through feedback, geo-localization, advanced services and multifunctional information. and in real time. Among the types of tourism in constant and rapid growth there is that linked to cultural heritage, with the inevitable repercussions on local economies, destinations and local communities. Cultural tourism attracts an increasing number of tourists / travelers with changing needs; no longer and not only linked to the search for fun but, also, to those of new experiences aimed at satisfying an intellectual, personal, and emotionally satisfying involvement. The importance of innovation, also seen as a new support for the tourist development of the territories, is translated through ICT that facilitate the use of the territory, but also as a system of informal networks between the population and the territories. The transformative power of intelligent technologies not only in terms of economic potential but also of social and experiential dimensions is now widely recognized. From this perspective, the new initiative of the European Commission "EUROPEAN CAPITAL OF SMART TOURISM - ECoST" should be read, which through the holding of a competition aims to identify the European Capital of Intelligent Tourism. In addition to the deepening of the most recent theoretical conceptualizations, the study will be based on the deepening of the ECoST Project and on the examination of the potential of some Italian cities.
\end{abstract}

Key words: Tourism, sustainability, development, technology, cities, potentiality

Citation: Ivona, A. (2020). European Urban Regeneration through Intelligent Applications. Central European Journal of Geography and Sustainable Development, 2(2), 15-23. https://doi.org/10.47246/CEJGSD.2020.2.2.2

https://doi.org/10.47246/CEJGSD.2020.2.2.2

| Full text | 